\title{
Primary pancreatic hydatid cyst: a case report and literature review
}

\author{
Yilei $\mathrm{Wu}^{1+}$, Jun Gong ${ }^{2,3+}$, Wei Xiong ${ }^{2,3}$, Xiaojiong Yu ${ }^{2,3^{*}}$ and Xiangyu $\mathrm{Lu}^{2,3^{*}}$
}

\begin{abstract}
Background: Hydatid cysts are parasitic zoonoses that often occur in the liver. Pancreatic hydatid cysts are very rare and are usually misdiagnosed as pancreatic cystadenomas. At present, surgical resection combined with albendazole administration is the standard treatment for pancreatic hydatid cysts. However, making accurate preoperative diagnoses and avoiding intraoperative cystic rupture are challenges for surgeons.

Case presentation: A 28-year-old woman from the pastoral area presented to the surgical office complaining of abdominal pain and new-onset jaundice that began 9 days earlier. An enhanced computed tomography scan demonstrated a $6.0 \times 5.3 \mathrm{~cm}$ pancreatic head cystic mass that compressed the common bile duct and induced choledochectasia. The preoperative diagnosis was pancreatic head cystadenoma, and laparotomic pancreaticoduodenectomy was initiated successfully. The intra- and postoperative diagnosis was pancreatic hydatid cyst. The patient was discharged uneventfully 7 days after the operation. A 1-year course of albendazole (15 mg/kg/day) was admitted.

Conclusion: Pancreatic hydatid cysts are rare and often misdiagnosed as other types of cysts. History of living in an area in which the causative organism is endemic and positive anti-echinococcus lgG antibody status could help with the diagnosis. Radical resection combined with oral albendazole administration is the standard treatment for pancreatic hydatid cysts. Avoiding perioperative cystic rupture and abdominal echinococcosis implantation metastasis is crucial for the success of the operation.
\end{abstract}

Keywords: Pancreas, Hydatid cyst, Diagnosis, Treatment, Case report

\section{Background}

Hydatid disease is a cosmopolitan zoonosis caused by the larvae of Echinococcus granulosus [1]. Hydatid disease is observed in the Northern Hemisphere, especially in China, the Russian Federation, continental European countries and North America [2]. Hydatid cysts often occur in the liver [3], and some extrahepatic organs including a rare form in the pancreas [4]. At present, some case reports of primary pancreatic hydatid cysts have been published [5-7]. However, the diagnosis is

\footnotetext{
*Correspondence: 18981838879@163.com; 523971162@qq.com

${ }^{\dagger}$ Yilei Wu and Jun Gong have contributed equally to this work

${ }^{2}$ The Second Department of Hepatobiliary Surgery, Sichuan Provincial

People's Hospital, University of Electronic Science and Technology

of China, Chengdu 611731, Sichuan, China

Full list of author information is available at the end of the article
}

challenging due to its low morbidity, and the surgical procedure varies because of the different locations of the lesions and the understanding of this disease. In this article, we present a primary pancreatic hydatid disease case report and review published primary pancreatic hydatid cyst reports for better diagnosis and management.

\section{Case presentation \\ Patient information}

A 28-year-old woman presented to our department with body itching for more than ten days and jaundice for nine days. This patient had a long-term history of living in an area in which echinococcosis is endemic. Medical examination demonstrated yellow discoloration in both the skin and sclera, and abdominal examination was negative. After admission, the laboratory tests indicated a serum 
total bilirubin (Tbil) level of $264.0 \mu \mathrm{mol} / \mathrm{L}(5-22 \mu \mathrm{mol} / \mathrm{L})$, conjugated bilirubin (Dbil) level of $205.6 \mu \mathrm{mol} / \mathrm{L}$ $(0-7 \mu \mathrm{mol} / \mathrm{L})$ and unconjugated bilirubin (Ibil) level of $58.4 \mu \mathrm{mol} / \mathrm{L}(0-20 \mu \mathrm{mol} / \mathrm{L})$. Serum tumor markers, including carbohydrate antigen 19-9, $\alpha$-fetoprotein and carcinoembryonic antigen, were not present. On the imaging examination, an emergency computed tomography $(\mathrm{CT})$ scan indicated a $6.0 \times 5.3 \mathrm{~cm}$ cystic lesion in the head of the pancreas adjacent to the lower bile duct and main pancreatic duct that induced expansion. There were no solid nodules or calcifications in this lesion, and a slightly higher lesion density with a curved mild calcification was observed at the edge of the cyst (Fig. 1). Magnetic resonance imaging (MRI) indicated the same signals at the center of the lesion and a high signal around the wall of the capsule, suggesting local diffusion limitation. MRCP imaging demonstrated that the bile duct and main pancreatic duct were clearly dilated, and the cyst communicated with the pancreatic bile duct (Fig. 2). Based on the preoperative examination, a diagnosis of pancreatic cystadenoma was made.

\section{Surgical procedure}

During the laparotomy, a cyst lesion located in the pancreatic head was detected, which was adjacent to the duodenum and invaded the main pancreatic duct. After the cyst fluid was completely aspirated, the internal cyst collapsed and separated from what was previously considered the cyst wall (Fig. 3). The intraoperative pictures demonstrated signs of hydatid cysts (CE-1). The pancreaticoduodenectomy procedure was initiated successfully, and a "Child type" chongio-/gastric/pancreatic/jejunal anastomosis was performed. The patient was discharged uneventfully 7 days after the operation. A 1-year course of albendazole $(15 \mathrm{mg} / \mathrm{kg} /$ day $)$ was admitted and no recrudescence was detected in the postoperative 2 years. Pathological results indicated the presence of Echinococcosis granulosus accompanied by inflammatory cell infiltration and eosinophilic infiltration (Fig. 4).

\section{Literature review}

A literature search was initiated to review primary pancreatic hydatid cysts. Based on our search results (Table 1), 22 papers in PubMed reported 33 cases of primary pancreatic hydatid cysts from 2011 to 2021 [8-29]. In the 33 cases, 14 cases had cysts located in the pancreatic head, and 15 cases had lesions in the body/tail. Nineteen cases reported serum IgG levels, whereas the results of 8 cases were negative.

\section{Discussion and conclusion}

Primary pancreatic hydatid cysts account for $0.14-2 \%$ of the total number of systemic echinococcoses [21]. Primary pancreatic hydatid cysts are caused by the Echinococcus granulosus hookworm entering the systemic circulation and traveling to the pancreas through two barriers, including the liver and lung. Primary pancreatic hydatid cysts often occur in the pancreatic head rather than body/tail because of richer blood supply for the pancreatic head [26]. However, there are 12 cases occurred in the pancreatic head and 12 cases occurred in the pancreatic body/tail in a total of 33 cases based on the literature review. The reason for the comparable occurring rate is the limited reviewed manuscripts.
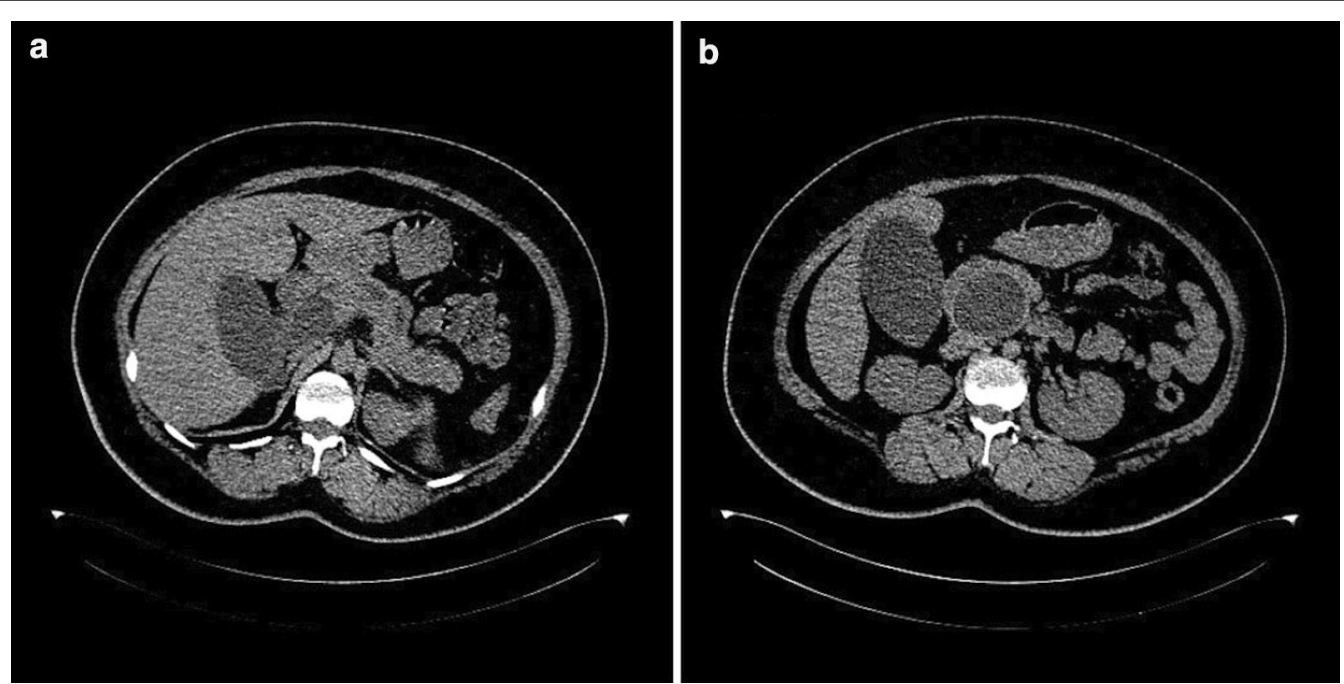

Fig. 1 CT scans of the pancreatic hydatid cyst. a pancreatic cyst inducing bile duct and main pancreatic duct expanding; b pancreatic head hydatid cyst 

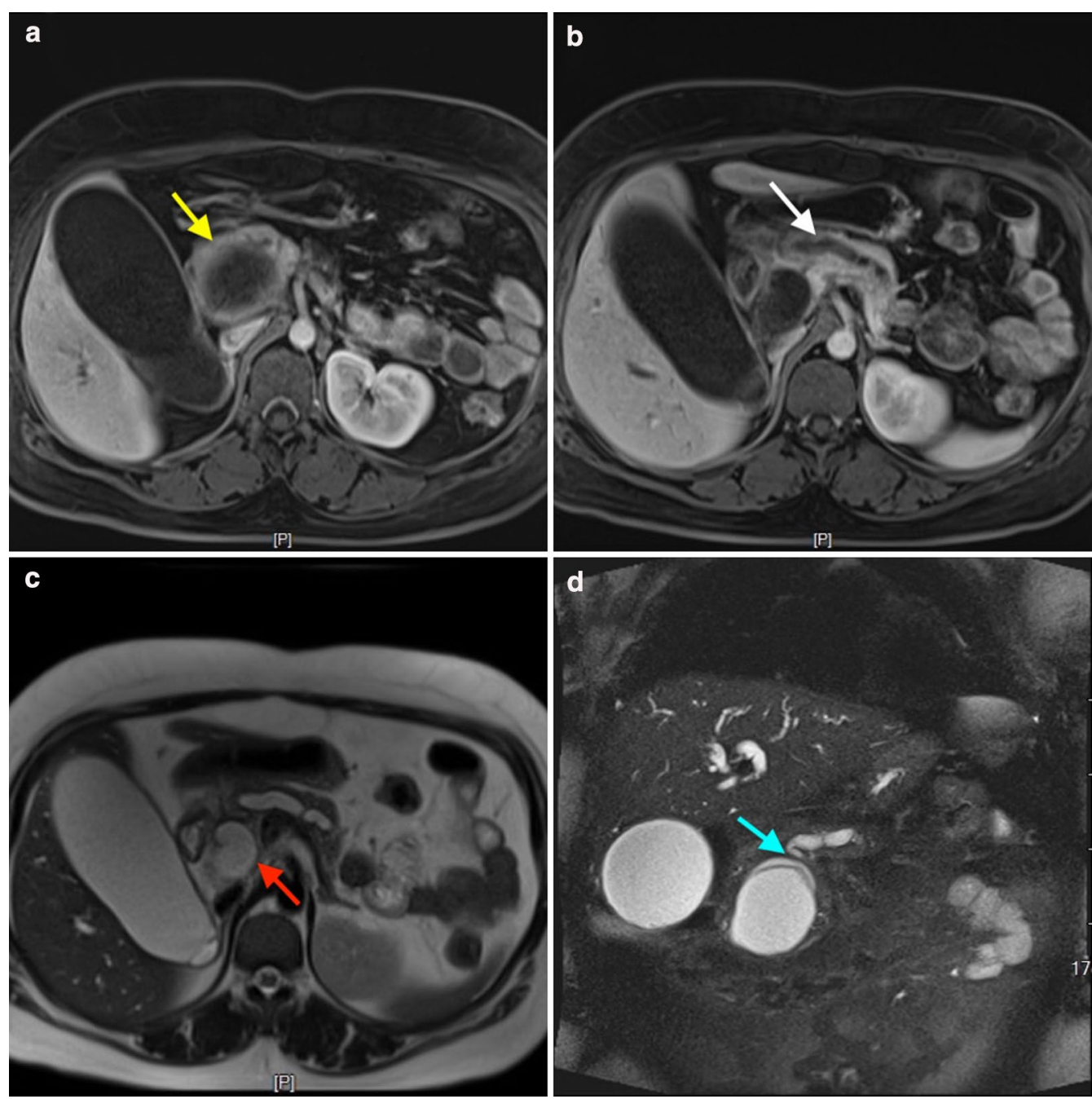

Fig. $2 \mathrm{MRl}$ of the pancreatic hydatid cyst. a The hydatid cyst mass (yellow arrow); $\mathbf{b}$ expanded main pancreatic duct (white arrow); c expanded bile duct (red arrow); $\mathbf{d}$ the hydatid cyst invaded the main pancreatic duct (blue arrow)

There are no specific clinical signs when the cyst is located in the pancreatic body/tail, whereas obstructive jaundice may occur when the lesion is in the head of the pancreas, such as the presented case. Also, some cases may present acute pancreatitis firstly because of the main pancreatic duct obstruction [9, 12]. Because of its rare incidence, pancreatic hydatid cysts are often misdiagnosed as other cyst types, such as pancreatic cystadenoma or cystadenocarcinoma. For the cases with suspected pancreatic hydatid cysts, most had the characteristics of living in areas where echinococcosis is endemic and a history of close contact with sheep or dogs. These characteristics and imaging data should be combined to diagnose echinococcosis.

Enhancing CT scans, MRI and/or contrast-enhanced ultrasound examinations facilitate diagnosis. The characteristics of signals or multiple subcysts, calcifications and consolidation may be present in the resulting images. Kerimoglu et al. demonstrated that mild enhancement of the medial edge of the capsule wall might occur [30]. In our case, the image of the pancreatic tail shows a single capsule with a clear boundary. The cross-section image shows local nodular thickening of the cystic wall, and it is difficult to differentiate hydatid cysts from other cystic lesions of the pancreas. Also, contrast-enhanced ultrasound examinations may help for the identification because the contrast medium could enter the internal septations of cystadenoma or cystadenocarcinoma, whereas the cystic echinococcosis presented non-contrast medium entered in the sub-cysts, and the sub-cysts could move with the patient's position changing [31]. Serum-positive anti-echinococcal IgG antibody 


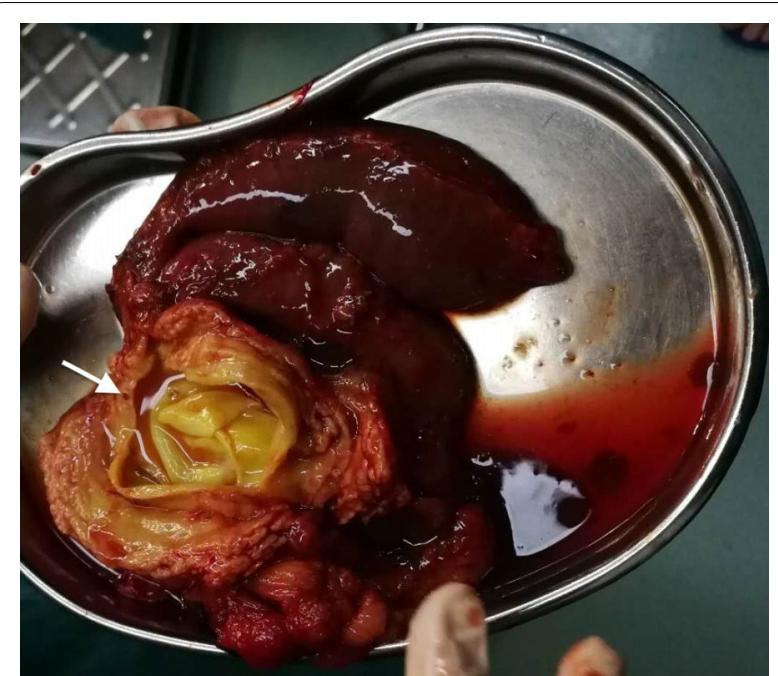

Fig. 3 The resected mass. The main pancreatic duct was invaded (white arrow)

status could help with the diagnosis, whereas which may be present due to the patient coming into contact with Echinococcus while living in an endemic area, rather than the assumed pancreatic hydatid cyst. In the reviewed literature, there are only 11 cases with positive anti-echinococcus IgG antibody in the 19 cases of confirmed pancreatic hydatid cyst.

Several surgical procedures have been described for the treatment of pancreatic hydatid cysts depending on their location [32]. Presently, available treatment options include radical resection, internal capsule stripping and external capsule removal (subadventitial total exocystectomy). In our case, the cyst was located in the pancreatic head, involved the main pancreatic duct and caused obstructive jaundice due to compression of the common bile duct; therefore, we performed pancreaticoduodenectomy. Based on the literature review, surgical drainage procedures have also been recommended but should not be the first selection because of the risk for abdominal intraperitoneal hydatid cyst implantation and metastasis. Additionally, cyst fluid overflow should be avoided during surgery.

In conclusion, pancreatic hydatidosis is a rare disease, and preoperative diagnosis of isolated pancreatic hydatid cysts in endemic regions is infrequent. It is difficult to differentiate between benign and malignant tumors of the pancreas before surgery. CT, MRI and/or contrast-enhanced ultrasound examination could be used to evaluate the malignant potential of the cyst and the presence of any connection with the main pancreatic duct. To clarify the relationship between cysts and the pancreatic duct, ERCP can be used to identify unknown cysts [33]. For cases strongly suspected to be pancreatic hydatids, preoperative evaluation should be combined with radiography and laboratory examination. A surgical procedure to prevent intra-abdominal spread with albendazole therapy thereafter may be an effective treatment for the disease.

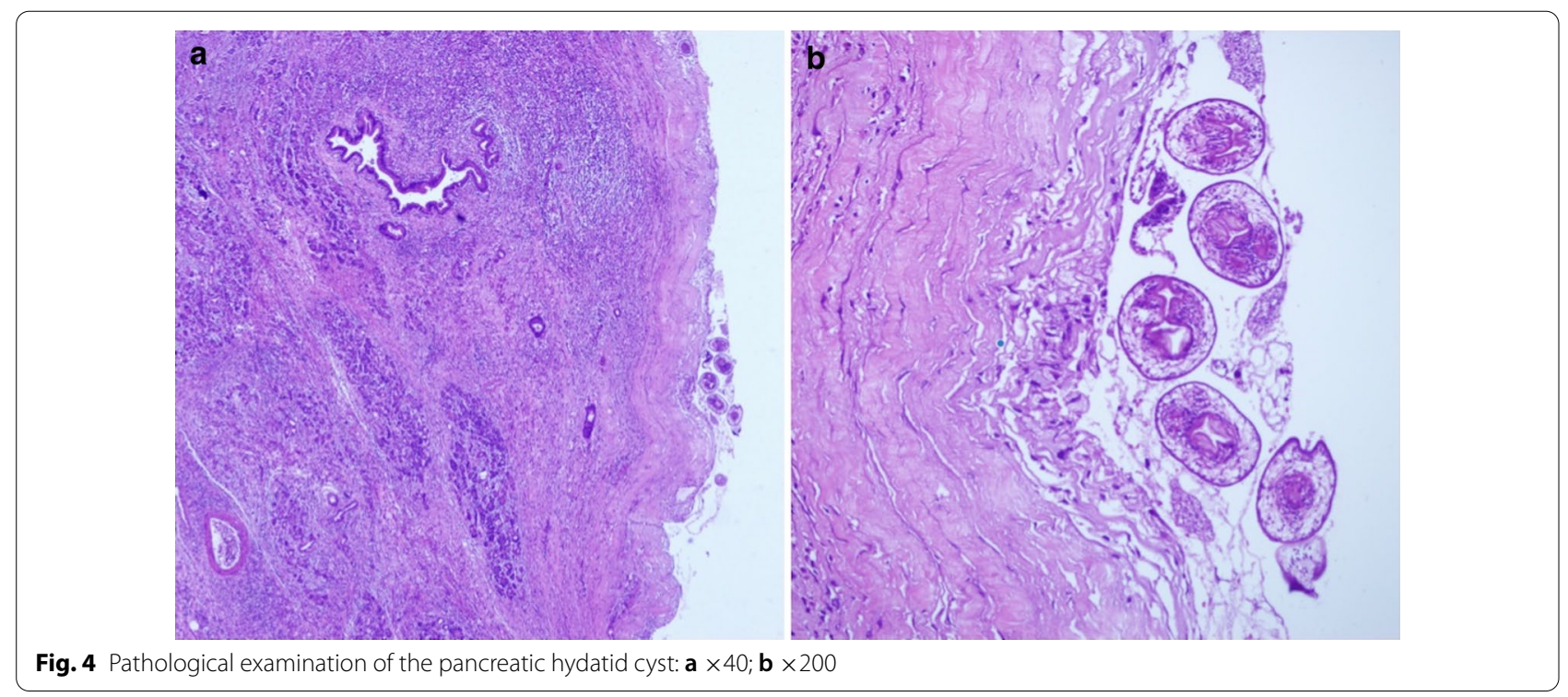


Table 1 Literature review of the primary pancreatic hydatid cyst in PubMed (2011-2021)

\begin{tabular}{|c|c|c|c|c|c|c|c|}
\hline First author [ref] & Case count & $\operatorname{Sex}(M / F)$ & Age (year) & Location & Cyst size $(\mathrm{mm})$ & Serology & Surgical procedure \\
\hline Tavusbay [18] & 1 & $\mathrm{~F}$ & 48 & Head & $28 \times 25$ & Negative & Partial cystectomy + omentoplasty \\
\hline Agrawal [10] & 1 & $\mathrm{~F}$ & 5 & Head & $120 \times 110$ & NS & $\begin{array}{l}\text { Enucleation + cholangiography + cholecystec- } \\
\text { tomy }+ \text { cystography }\end{array}$ \\
\hline Bhat [29] & 1 & $\mathrm{~F}$ & 4 & Head & $100 \times 150 \times 70$ & Negative & Partial cystectomy + drainage \\
\hline Masoodi [24] & 1 & M & 45 & Tail & $70 \times 60$ & Positive & Distal pancreatectomy + splenectomy \\
\hline Varshney [16] & 1 & M & 35 & Tail & NS & Positive & Distal pancreatectomy \\
\hline Suryawanshi [9] & 1 & M & 20 & Head & $80 \times 80$ & NS & Cyst evacuation + omentoplasty \\
\hline Karaman [19] & 1 & M & 32 & Neck & $55 \times 45$ & Positive & Percutaneous drainage \\
\hline Makni [12] & 1 & M & 38 & Tail + body & $100 \times 90$ & Positive & Distal pancreatectomy + splenectomy \\
\hline Mandelia [22] & 1 & M & 6 & Head & $54 \times 41$ & NS & Enucleation + cholangiography \\
\hline Yarlagadda [17] & 1 & M & 43 & Tail & $180 \times 170$ & NS & Distal pancreatectomy + splenectomy \\
\hline \multirow[t]{12}{*}{ Trigui [13] } & 12 & $\mathrm{~F}$ & 21 & Tail & NS & NS & Distal pancreatectomy \\
\hline & & M & 13 & Tail + body & NS & NS & Partial cystectomy + drainage \\
\hline & & M & 15 & Head & NS & NS & Partial cystectomy + drainage \\
\hline & & M & 26 & Head & NS & NS & Partial cystectomy + drainage \\
\hline & & $\mathrm{F}$ & 50 & Head & NS & NS & Partial cystectomy + drainage \\
\hline & & $\mathrm{F}$ & 37 & Head & 25 & Negative & Pancreaticoduodenectomy \\
\hline & & M & 8 & Head & $83 \times 76$ & Positive & Partial cystectomy + duodenal fistula treatment \\
\hline & & $\mathrm{F}$ & 26 & Tail + body & 40 & Positive & Distal pancreatectomy + splenectomy \\
\hline & & $\mathrm{F}$ & 61 & Tail & NS & Positive & Distal pancreatectomy + splenectomy \\
\hline & & $\mathrm{F}$ & 11 & Head & NS & Negative & Cysto-duodenal anastomosis \\
\hline & & $\mathrm{F}$ & 16 & Body & NS & Positive & Partial cystectomy + drainage \\
\hline & & $\mathrm{F}$ & 11 & Head & 50 & NS & Cysto-duodenal anastomosis \\
\hline Vasilescu [27] & 1 & $\mathrm{~F}$ & 63 & Isthmus + body & $110 \times 86$ & Negative & $\begin{array}{l}\text { Drainage + lavage with hypertonic } \\
\text { serum + partial cystectomy }\end{array}$ \\
\hline Deak [23] & 1 & M & 34 & Head & $60 \times 40 \times 40$ & Negative & Enucleation + partial cystectomy \\
\hline Alsaid [20] & 1 & M & 34 & Body & $350 \times 200 \times 150$ & NS & Partial cystectomy + drainage \\
\hline Bakkaly [14] & 1 & $\mathrm{~F}$ & 5 & Head & $57 \times 31$ & Positive & Partial cystectomy + drainage \\
\hline Sethi [8] & 1 & $\mathrm{~F}$ & 48 & Tail + body & $110 \times 140$ & Negative & NS \\
\hline Lada [26] & 1 & $\mathrm{~F}$ & 18 & NS & $120 \times 130 \times 110$ & Negative & Partial cystectomy + drainage \\
\hline Ahmed [21] & 1 & $\mathrm{~F}$ & 40 & Body & $55 \times 57$ & Positive & Partial cystectomy + drainage \\
\hline Elaffand [15] & 1 & M & 34 & Body + tail & $110 \times 80$ & Positive & Partial cystectomy + cystogastrostomy \\
\hline Hiremath [11] & 1 & $\mathrm{~F}$ & 48 & Neck & $80 \times 100 \times 82$ & NS & Partial cystectomy + drainage \\
\hline Kisaoglu [28] & 1 & $\mathrm{~F}$ & 58 & NS & $50 \times 30$ & NS & $\begin{array}{l}\text { Splenectomy + distal pancreatectomy + chol- } \\
\text { ecystectomy }\end{array}$ \\
\hline Jonkov [25] & 1 & $\mathrm{~F}$ & 61 & Body +tail & $55 \times 75$ & NS & Distal pancreatectomy \\
\hline
\end{tabular}

NS not-stated

\section{Abbreviations}

Tbil: Total bilirubin; Dbil: Conjugated bilirubin; Ibil: Unconjugated bilirubin; CT: Computed tomography; MRI: Magnetic resonance imaging; MRCP: Magnetic Resonance Cholangiopancreatography; ERCP: Endoscopic Retrograde Cholangio Pancreatography.

\section{Acknowledgements}

The authors thank AJE for editing grammar, spelling, and other common errors.

\section{Authors' contributions}

$X L$ and $X Y$ designed the study; JG, YW and WX collected the patient's clinical data; XL and YW analyzed the data; XL wrote the paper. All authors read and approved the final manuscript.

\section{Funding}

None.

Availability of data and materials

All data generated or analyzed during this study are included in this published article. 


\section{Declarations}

Ethics approval and consent to participate

An approval from the hospital board committee is taken for the procedure and case report publication.

\section{Consent for publication}

Written informed consent for publication was obtained from the participant. There aren't any personal or clinical details along with the images to be published in this study.

\section{Competing interests}

The authors declared no conflict of interest.

\section{Author details}

'Department of Medical Records Statistics, Sichuan Provincial People's Hospital, University of Electronic Science and Technology of China, Chengdu 611731, Sichuan, China. ${ }^{2}$ The Second Department of Hepatobiliary Surgery, Sichuan Provincial People's Hospital, University of Electronic Science and Technology of China, Chengdu 611731, Sichuan, China. ${ }^{3}$ Chinese Academy of Sciences Sichuan Translational Medicine Research Hospital, Chengdu 610072, Sichuan, China.

Received: 1 December 2020 Accepted: 7 April 2021

Published online: 13 April 2021

\section{References}

1. Agudelo Higuita NI, Brunetti E, McCloskey C. Cystic echinococcosis. J Clin Microbiol. 2016;54(3):518-23.

2. Deplazes P, Rinaldi L, Alvarez Rojas CA, Torgerson PR, Harandi MF, Romig T, et al. Global distribution of alveolar and cystic echinococcosis. Adv Parasitol. 2017;95:315-493.

3. Li Y, Ma Z, Tuxun T, Li Z, Meng Y, Chen X. The application of laparoscopy combined with indocyanine green fluorescence imaging technique for hepatic cystic echinococcosis. BMC Surg. 2020;20(1):249.

4. Seyed Reza M, Houman Khajouei K. Epigastric mass due to a hydatid cyst of the pancreas. A case report and review of the literature. JOP. 2007:8:232-4

5. Cağlayan K, Celik A, Koç A, Kutluk AC, Altinli E, Celik AS, Köksa N. Unusual locations of hydatid disease: diagnostic and surgical management of a case series. Surg Infect (Larchmt). 2010;11(4):349-53.

6. Malekzadeh R, Pezeshky B, Hormazdi M, Rakhshani N, Soroush Z. Primary hydatid disease of the pancreas. Arch Iran Med. 2006;9:291-2.

7. Chammakhi-Jemlinull W, Mekaouernull S, Miaouinull A, Daghfousnull A Mzabinull H, Cherifnull A, et al. Hydatid cyst of the pancreas presenting with acute pancreatitis. J Radiol. 2010;91:797-9.

8. Sethi S, Puri SK, Agarwal A. Primary pancreatic hydatid: a rare cystic lesion of the pancreas. Am J Trop Med Hyg. 2017:96(4):763-4

9. Suryawanshi $P$, Khan $A Q$, Jatal S. Primary hydatid cyst of pancreas with acute pancreatitis. Int J Surg Case Rep. 2011;2(6):122-4.

10. Agrawal S, Parag P. Hydatid cyst of head of pancreas mimicking choledochal cyst. BMJ Case Rep. 2011;2011:bcr0420114087.

11. Hiremath B, Subramaniam N, Boggavarapu M. Primary pancreatic hydatid cyst: an unexpected differential diagnosis. BMJ Case Rep. 2015:2015:bcr2015211377.

12. Makni A, Jouini M, Kacem M, Safta ZB. Acute pancreatitis due to pancreatic hydatid cyst: a case report and review of the literature. World J Emerg Surg. 2012;7(1):7.

13. Trigui A, Rejab H, Guirat A, Mizouni A, Ben Amar M, Mzali R, et al. Hydatid cyst of the pancreas. About 12 cases. Ann Ital Chir. 2013;84:165-70.
14. Bakkaly AE, Merouane N, Dalero O, Oubeja H, Erraji M, Ettayebi F, et al. Primary hydatid cyst of the pancreas of the child: a case report. Pan Afr Med J. 2017:28(27):229.

15. Elaffand A, Vijay A, Mohamed S, Al-Battah HH, Youssef A, Farahat A. Echinococcal cyst of the pancreas with cystopancreatic duct fistula successfully treated by partial cystectomy and cystogastrostomy. J Surg Tech Case Rep. 2015:7(2):48-50.

16. Varshney M, Shahid M, Maheshwari V, Siddiqui MA, Alam K, Mubeen A, et al. Hydatid cyst in tail of pancreas. BMJ Case Rep. 2011;2011:bcr0320114027.

17. Yarlagadda P, Yenigalla BM, Penmethsa U, Myneni RB. Primary pancreatic echinococcosis. Trop Parasitol. 2013;3(2):151-4.

18. Tavusbay C, Gur OS, Durak E, Haciyanli M, Genc H. Hydatid cyst in abdominal incisional hernia. Bratisl Lek Listy. 2011:112:287-9.

19. Karaman B, Battal B, Ustunsoz B, Ugurel MS. Percutaneous treatment of a primary pancreatic hydatid cyst using a catheterization technique. Korean J Radiol. 2012;13(2):232-6

20. Alsaid B, Alhimyar M, Rayya F. Pancreatic hydatid cyst causing acute pancreatitis: a case report and literature review. Case Rep Surg. 2018;5(2018):9821403.

21. Ahmed Z, Chhabra S, Massey A, Vij V, Yadav R, Bugalia R, et al. Primary hydatid cyst of pancreas: case report and review of literature. Int I Surg Case Rep. 2016;27:74-7.

22. Mandelia A, Wahal A, Solanki S, Srinivas M, Bhatnagar V. Pancreatic hydatid cyst masquerading as a choledochal cyst. J Pediatr Surg. 2012;47(11):e41-4.

23. Deak J, Zadori G, Csiszko A, Damjanovich L, Szentkereszty Z. Hydatid disease of pancreas: a case report. Interv Med Appl Sci. 2019;11(1):74-6.

24. Masoodi MI, Nabi G, Kumar R, Lone MA, Khan BA, Naseer Al Sayari K. Hydatid cyst of the pancreas: a case report and brief review. Turk J Gastroenterol. 2011:22(4):430-2

25. Jonkov A, Todorov R, Katibova S. Clinical case of echinococcus of the pancreas. Khirurgiia (Sofiia). 2014;25:46-50.

26. Lada PE, Termengo D, Caceres G, Sanchez Tacone C, Caballero F, Sonzini AP. Primary hydatid cyst of the pancreas. Rev Fac Cien Med Univ Nac Cordoba. 2017:74:33-6.

27. Vasilescu A, Tarcoveanu E, Crumpei F, Blaj M, Bejan V, Bradea C. Laparoscopic approach of primary hydatid cyst of the pancreas - case report and literature review. Chirurgia (Bucur). 2020;115(2):261-6.

28. Kisaoglu A, Ozogul B, Atamanalp SS, Pirimoglu B, Aydinli B, Korkut E. Incidental isolated pancreatic hydatid cyst. Turkiye Parazitol Derg. 2015:39(1):75-7.

29. Bhat NA, Rashid KA, Wani I, Wani S, Syeed A. Hydatid cyst of the pancreas mimicking choledochal cyst. Ann Saudi Med. 2011;31(5):536-8.

30. Kerimoglu U, Kapicioglu S, Emlik D, Arazi M, Ural O. Case 161: Hydatid disease with water lily sign manifesting as a soft-tissue mass in the calf of a child. Radiology. 2010;256(3):1007-10.

31. Yang C, Yang H, Deng S, Zhang Y. Hepatobiliary and Pancreatic: Hepatic cystadenoma mimics hepatic cystic echinococcsis. J Gastroenterol Hepatol. 2020;35(7):1098

32. Dziri C, Dougaz W, Bouasker I. Surgery of the pancreatic cystic echinococcosis: systematic review. Transl Gastroenterol Hepatol. 2017;2:105.

33. Akbulut S, Yavuz R, Sogutcu N, Kaya B, Hatipoglu S, Senol A, et al. Hydatid cyst of the pancreas: report of an undiagnosed case of pancreatic hydatid cyst and brief literature review. World J Gastrointest Surg. 2014:6(10):190-200.

\section{Publisher's Note}

Springer Nature remains neutral with regard to jurisdictional claims in published maps and institutional affiliations. 